\title{
Intolerance of Uncertainty and Health-Related Anxiety in Youth amid the COVID-19 Pandemic: Understanding and Weathering the Continuing Storm
}

\author{
Ciera Korte ${ }^{1} \cdot$ Robert D. Friedberg $^{1}$ (1) $\cdot$ Tammy Wilgenbusch $^{2}$. Jennifer K. Paternostro ${ }^{2} \cdot$ Kimberly Brown $^{1}$. \\ Anusha Kakolu ${ }^{1}$. Josh Tiller-Ormord ${ }^{1} \cdot$ Raman Baweja $^{3} \cdot$ Marissa Cassar $^{1} \cdot$ Agatha Barnowski $^{1}$ - Yasaman Movahedi ${ }^{1}$. \\ Krista Kohl ${ }^{2}$. William Martinez ${ }^{4} \cdot$ Sandra Trafalis $^{1} \cdot$ Yan Leykin ${ }^{1}$
}

Accepted: 19 August 2021 / Published online: 3 September 2021

○ The Author(s), under exclusive licence to Springer Science+Business Media, LLC, part of Springer Nature 2021

\begin{abstract}
The COVID-19 pandemic is a public health crisis that continues to impact individuals worldwide. While children may be less susceptible to severe medical complications, they are nonetheless vulnerable to stress and anxiety associated with the pandemic. However, current understanding of psychological functioning and potential strategies to mitigate distress amid a pandemic is naturally limited. Consequently, this article is an attempt to fill that gap. Existing literature on pandemics, health-related anxieties, intolerance of uncertainty, and psychopathological sequelae is summarized within the context of the COVID-19 outbreak. Conclusions from the empirical data and emerging theoretical models are reviewed and synthesized. Finally, several potentially engaging and effective examples of developmentally appropriate interventions targeting intolerance of uncertainty and health-related anxieties in pediatric patients during the peri- and post-pandemic periods are described.
\end{abstract}

Keywords COVID-19 $\cdot$ Intolerance of uncertainty $\cdot$ Health-related anxieties $\cdot$ Cognitive-behavioral therapy

\section{Introduction}

The COVID-19 viral pandemic is a historic global health crisis that continues to wreak havoc on millions of lives. Taylor (2019) suggested health pandemics share certain features including being singular widespread traumatic events, often marked by waves, apparently indefinite to the public, and characterized by ambiguous endpoints. Uncertainty and health-related anxieties grow organically in the peri- and post-pandemic periods. People fear infection, ineffective prevention, inadequate intervention efforts, and uncontrolled

Robert D. Friedberg

rfriedberg@paloaltou.edu

1 Center for the Study and Treatment of Anxious Youth, Palo Alto University, Los Altos, CA, USA

2 Stead Family Children's Hospital, University of Iowa, Iowa City, IA, USA

3 Penn State Milton Hershey Medical Center, Penn State University College of Medicine, Hershey, PA, USA

4 Zuckerberg General Hospital, University of California-San Francisco, San Francisco, CA, USA viral spread (Taylor, 2019). Hypervigilance toward possible health risks likely increases during pandemics and often these perceptions inflate probability estimates of dire consequences.

In novel situations where uncertainty and ambiguity are rampant, children are especially vulnerable to developing maladaptive reactions to stress. The COVID-19 pandemic and the increased media coverage likely serve as "critical incidents" for accelerating health-related anxieties (HaigFerguson et al., 2020). Experts predict a surging number of young people-seeking clinical care for various behavioral health concerns during the peri- and post-pandemic period (Fegert et al., 2020; Golberstein et al., 2020; Loades et al., 2020; Marques de Miranda et al., 2020; Sanderson et al., 2020; Simon et al., 2020; Abbott, 2021).

With the emergence of the Delta variant of the COVID-19 virus, children are becoming more susceptible to infection (American Academy of Pediatrics \& Children's Hospital Association, 2021). Further, pandemics may leave children vulnerable to several adverse psychological sequelae since they experience many indirect effects a pandemic poses to public health and the global economy (Jiao et al., 2020). During the peri- and post-pandemic periods, anxiety 
spectrum disorders in pediatric populations are expected to rise dramatically (Czeisler et al., 2020). Health-related worries increase individuals' distress in response to a perceived threat to physical well-being (Taylor \& Asmundson, 2004; Asmundson et al., 2010). The emphasis on personal hygiene and handwashing as preventative measures for the spread of the virus may also increase OCD-related symptoms in children (Imran et al., 2020). For instance, Liu et al. (2020) found elevated PTSD and GAD rates among Chinese children and adolescents after the COVID-19 outbreak. Symptoms of distress within this population positively correlated with perceptions of the virus as threatening or stigmatizing. The sense of control and predictability which is so central to pediatric anxiety disorders is quite possibly compromised in young patients experiencing such an uncertain event as a pandemic (Chorpita \& Barlow, 1998).

Pandemics and their consequences create multiple adverse events such as death of loved ones, loss of employment, financial stressors, relationship conflicts, domestic violence, and child abuse (Taylor, 2019; Bryant et al., 2020). In addition, children with pre-existing medical and mental health conditions might not have access to necessary care (Sanderson et al., 2020). These young people then are more likely to experience increased worry about the pandemic and could also exhibit increased suicidal as well as nonsuicidal self-injurious behaviors (Fegert et al., 2020). Thus, the coronavirus poses not only a potential crisis for public health services but a behavioral health emergency as well.

Models for understanding psychological sequelae associated with global pandemics are under-developed. Unsurprisingly, treatment approaches to mitigate distress in the peri- and post-pandemic periods are similarly incipient. Consequently, researchers and clinicians need a conceptual scheme for understanding and intervening during these unprecedented periods. Intolerance of uncertainty (IU) is a dispositional psychological trait characterized by an intense fear of and diminished capacity for coping with the unknown (Carleton, 2016). Accordingly, IU may be a key variable for conceptualizing young people's health-related concerns during a viral outbreak and cognitive-behavioral interventions targeting this pathway are potentially good treatment options.

However, the last pandemic hitting the United States occurred over 100 years ago. Therefore, these theoretical concepts and treatment methods have not been examined in the current context of the viral outbreak. In order to provide proper background, this article begins with a discussion of pandemics' social and psychological impact. Next, healthrelated anxieties in youth during the COVID-19 outbreak are addressed. IU and its place on various developmental psychopathology trajectories are explained. Finally, drawing upon cognitive-behavioral theory, the article concludes with a description of potentially useful interventions that target health-related anxieties as well as intolerance of uncertainty in youth.

\section{The Social and Psychological Impact of Pandemics}

Pandemics lay bare and exacerbate health disparities present in communities. Historically, more impoverished populations in societies suffer longer and more intensely due to a pandemic's fallout (Mamelund, 2018; O'Sullivan \& Phillips, 2019; Taylor, 2019). In the first wave of the 1918 Flu Pandemic in Norway, the poor became ill earliest (Mamelund, 2018). Mamelund (2018) observed a negative correlation between socioeconomic status (SES) and morbidity levels with individuals from lower-income brackets getting infected at higher rates. Similarly, low-income families are currently experiencing more acute COVID-19 pandemic-related adversities due to family reorganization, food insecurity, lack of access to proper health care, employment as front-line workers, increased financial stress, and pre-existing mental health conditions (Valenzuela et al., 2020).

Minoritized groups are inordinately affected-physically, financially, and psychologically by COVID-19 (Moore et al., 2020; Phillips et al., 2020). Disproportionate morbidity and mortality rates are documented within Black, Indigenous, and People of Color (BIPOC) populations (Phillips et al., 2020). Many pediatric patients from traditionally marginalized groups are at increased risk for infection and complications due to high comorbidities. Latinx and African-American youth suffer higher prevalence rates of various medical conditions such as asthma, diabetes, sickle cell disease, and obesity which are listed risk factors for morbidity and mortality associated with COVID-19 infection (Rodriquez et al., 2020). Ethnic minority youth are a population that may be especially at-risk for behavioral and physical health disorders, but they encounter disparities in mental health services utilization, intensity, and quality when compared to White youth (Alegria et al., 2010). Therefore, psychological intervention strategies should be flexible enough to address high-risk populations as their needs change throughout the pandemic's lifecycle (Inchausti et al., 2020). Recommendations for repairing these disparities in behavioral health care services in the peri- and post-pandemic periods are discussed in the future directions section.

\section{Health-Related Anxieties in Youth Amid the COVID-19 Pandemic}

Although care providers are often unfamiliar with healthrelated anxieties in young patients, these worries are nonetheless relatively common (Villadsen et al., 2017; 
Haig-Ferguson et al., 2020). Health-related anxieties involve various physiological, emotional, cognitive, and behavioral symptoms (Taylor \& Asmundson, 2004; Asmundson et al., 2010; Haig-Ferguson et al., 2020; Rask et al., 2020). The condition occurs when individuals become preoccupied and excessively concerned with benign bodily sensations or physical changes (i.e., coughing, aching muscles) by interpreting them as signs of serious illness (Taylor \& Asmundson, 2004; Asmundson et al., 2010). The distorted perception of bodily cues leads to worry and emotional distress as well as various safety-seeking behaviors including social withdrawal, panic purchasing, and high healthcare utilization. Compulsive behaviors such as repetitive cleaning and handwashing can worsen amid the pandemic due to the risk of contracting the virus.

Young patients diagnosed with medical conditions repeatedly experience multiple health-related worries. More specifically, studies show elevated anxiety levels in pediatric populations diagnosed with diabetes (Ducat et al., 2014), functional abdominal pain (Shelby et al., 2013), coronary heart disease (Oliver et al., 2020), and asthma (Pateraki et al., 2018). Therefore, it seems reasonable to suspect that children with comorbid mental health disorders and medical conditions are more at risk for developing health-related anxieties during a pandemic due to contamination fears and worries about exacerbating their illnesses.

Developmental variations in symptom expression such as verbal expressiveness and safety seeking are apparent. Younger children may be less able to translate their distress into words than pre-adolescents and teenagers (Haig-Ferguson et al., 2020). Hence, younger patients may express their distress more through disruptive behaviors. Further, HaigFerguson and colleagues (2020) noted that younger patients might demonstrate safety-seeking behavior by obtaining reassurance from parents/caregivers whereas older patients are more likely to search online as a form of checking behavior during periods of crises such as pandemics.

As the pre-pandemic literature review indicates, the understanding of health-related anxieties in young patients is limited but expanding. However, the conceptualization of the psychological mechanisms associated health-related anxieties is somewhat rudimentary. Breaking a construct into related constituent parts adds to its validity (Cronbach $\&$ Meehl, 1955). In the next section, IU is offered as a potentially viable variable for decoding health related and other anxieties during the COVID-19 outbreak.

\section{Intolerance of Uncertainty}

Individuals with high IU find ambiguity unbearable and experience difficulty functioning in uncertain situations (Comer et al., 2009). IU manifests as worry, emotional distress, ineffective problem solving, and uncertainty avoidance (Dugas et al., 1998; Read et al., 2013; Rifkin \& Kendall, 2020a, b). Hebert and Dugas (2019) developed a vanguard conceptual model outlining IU's contributions to anxiety. The model posits that many unknowns punctuate unpredictable life events. Additionally, these ambiguous and novel circumstances naturally lead to feelings of uncertainty. When children and adolescents catastrophically misinterpret these uncertainties, their intolerance grows. The magnification of the threat that uncertainty poses leads to various adverse sequelae including distressing worry and anxiety. Accordingly, IU seems particularly well suited to explaining anxieties during an unprecedented pandemic.

Clearly, IU propels worry (Dugas et al., 1998; Carleton, 2016; Osmanağaoğlu et al., 2018; Evans et al., 2020; Rifkin \& Kendall, 2020b). Osmanağaoğlu et al. (2018) attributed nearly $40 \%$ of adolescents' variation in worry to IU. High levels of IU are associated with rumination and catastrophizing (Read et al., 2013; Satici et al., 2020). Moreover, IU contributes to avoidance, seeking reassurance, planning for worst-case scenarios, and excessive caution (Beesdo-Baum et al., 2012). Young people with elevated IU tend to overvalue worry as a problem-solving technique. Perhaps, this is a reason IU appears to be transdiagnostically connected to various anxieties.

\section{Pathways from IU to Various Forms of Child Psychopathology}

The relationship between IU and worry to multiple anxiety disorders is becoming increasingly clear (Kertz \& WoodruffBorden, 2013). For instance, health-related anxieties and IU appear connected. Not surprisingly, if children suffer from unpredictable health conditions and undergo unfamiliar medical procedures, uncertainty is likely to occur (Dugas et al., 2012). Children with chronic illnesses appear especially vulnerable to IU's adverse effects (Mertens et al., 2020). Oliver et al. (2020) reported that children with healthrelated anxiety associated with chronic illness experience elevated IU due to situational uncertainty revolving around unpredictable health procedures. In turn, this anticipatory worry regarding treatment further exacerbates initial healthrelated anxiety. The multiple uncertainties that accompany the COVID-19 pandemic likely accelerate greater IU and worries about health.

Substantial research connects IU with obsessive-compulsive disorder (OCD), generalized anxiety disorder (GAD), and social anxiety disorder (SAD) due to its relationship with worrying and catastrophizing. Doubt and IU are seen as core features of OCD (Gillett et al., 2018; Cervin et al., 2020). Gillett and colleagues (2018) claimed that compulsions such as checking behaviors could be seen as attempts to reduce uncertainty or ambiguity. 
These reactions are likely to become emotionally intensified during the peri- and post-pandemic periods catalyzing greater maladaptive safety-seeking behaviors (Asmundson \& Taylor, 2020).

IU also lays a path toward GAD and SAD (Dugas et al., 1998; Carleton, 2016; Evans et al., 2020). Hearn et al., (2017a, b) found significantly higher IU among children and adolescents with SAD and GAD than cohorts without anxiety disorders. This is especially important since the expectation of rising tides of SAD and GAD in the periand post-pandemic periods seems quite reasonable.

Elevated IU may also underlie panic disorder (PD). IU ignites hypervigilance to interoceptive cues such as somatic symptoms. Lieberman et al. (2016) pointed to a combination of cognitive rigidity and heightened IU as primary catalysts for PD. Not only do individuals with PD experience elevated IU and hypervigilance towards unpredictable internal stimuli (e.g., dizziness and sweating), but they are also more likely to engage in covert avoidance which can manifest in the flight/freeze response (Nelson et al., 2016). Repeated scanning of one's bodily sensations seems rather likely during a viral outbreak.

In sum, although IU serves as a mechanism of action in multiple disorders, the specific function is currently unclear (Palitz et al., 2019b). IU could be a determinative factor leading to various conditions or represent a contributing feature acting in consort with other components. IU may also be a vulnerability factor that potentially predicts the emergence of numerous symptoms. Therefore, a working model to guide intervention is necessary.

\section{A Working Model for Targeting IU in CBT with Youth}

The reviewed literature suggests a diathesis-stress model could be a useful clinical heuristic for conceptualizing and treating youth experiencing distress during the pandemic. Pandemics create multiple new rules and constraints which contribute to a rapidly changing environment and requires flexible adaptation. As Fig. 1 graphically illustrates, the pandemic serves as a stressor and triggers IU due to its characteristic properties. The pandemic represents a "looming vulnerability" due to its changing nature and perceived potential for increasing emotional intensity (Pincotti et al., 2021). Since IU is considered a dispositional variable, the construct likely serves as a diathesis. Heightened IU then propels catastrophizing, magnification of threat, hypervigilance, rumination, worry, reassurance-seeking/checking, fears of loss/lack of control, and avoidance. In particular, avoidance, reassurance-seeking, and checking reflect typical safety-seeking behaviors common to health-related anxieties as well as other disorders. Further, many of these behaviors are hallmark symptoms of subthreshold or clinical disorders such as GAD and SAD. Finally, IU acts as both a causal factor by increasing vulnerability to anxiety spectrum symptoms and a maintaining factor by being negatively reinforced via various safety-seeking behaviors (e.g., checking or avoidance).

Figure 1 maps out a cluster of potential treatment targets. A CBT-oriented approach to treatment seems a promising strategy to combat the array of symptoms and potential comorbidities. In the following section, we explain and describe various treatment procedures for use in the periand post-pandemic periods.
Fig. 1 Map of potential treatment targets

\section{PANDEMIC}

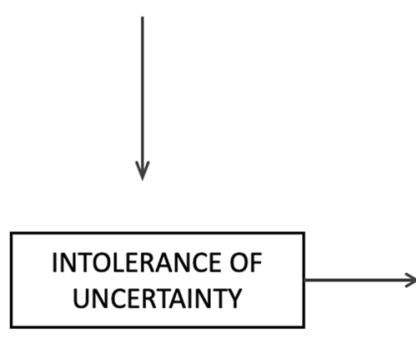

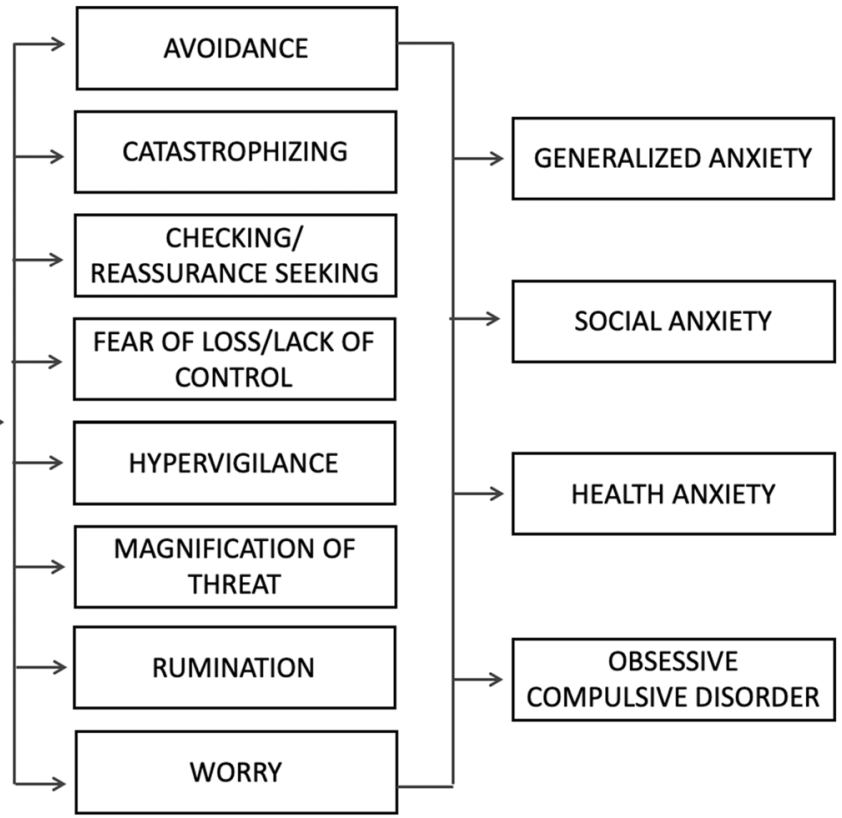




\section{Treating IU and its Sequelae}

The unexpected, unknown, and dynamic nature of the pandemic is stoking feelings of uncertainty among many people. With greater widespread doubt and misgivings, IU likely assumes a larger role in health-related anxiety problems. Consequently, equipping clinicians with methods that target IU and health-anxiety-related problems is a potentially effective intervention strategy. Fortunately, contemporary Cognitive Behavior Therapy (CBT) spectrum approaches offer a full cache of procedures for combatting IU and its clinical sequelae especially healthrelated anxiety (Higa-McMillan et al., 2016; Palitz et al., 2019a) and OCD (Storch et al., 2018). In particular, psychoeducation, cognitive restructuring procedures, and exposure/behavioral experiments are likely suitable treatment options. All these methods help young patients attain a greater sense of control and mastery. The following section delineates how applying these treatment strategies may mitigate pandemic-related anxiety and IU in pediatric patients.

A recent study noted that lack of information as well as misinformation are major catalysts to children's pandemic-related anxieties (Shahrbabaki et al., 2021). Further, Radanovic et al. (2021) found that children's worries increased with greater exposure to threat messages originating from parents as well as from outside sources (e.g., peers, news reports, internet, social media, etc.). These findings are consistent with Rachman's (1977) seminal work stating that fear is transmitted through verbal threat messaging. Many young patients do not possess sufficient information to combat threat messaging during the pandemic and lack adequate coping skills. Consequently, psychoeducational strategies are especially valuable for treating youth with pandemic-related worries because they empower pediatric patients and serve to initially modify IU (Radanovic et al, 2021). Table 1 lists several recommendations for creative psychoeducational interventions.

Catastrophic predictions, overestimations of danger/ threat, and what if thinking are common in anxious youth (Friedberg \& McClure, 2015). These thoughts commonly confuse possibility with probability and are rife with uncertainty. More specifically, children's anxiogenic beliefs during the pandemic include thoughts such as "I am afraid I am going to die because of COVID-19," "I get anxious or nervous from watching the news," "I am afraid I am going to spread the virus to others," and "I worry about being infected (Shahrbabaki et al., 2021)." However, changing these cognitions is difficult and especially challenging during a pandemic where objective threat exists. Therefore, skillful application of cognitive restructuring procedures is necessary. In this way, young patients learn to test their predictions and more accurately appraise the probabilities as well as the magnitude of potential dangers. Two child-friendly cognitive restructuring procedures are described in Table 1.

Contamination fears and worries about becoming ill are exacerbated by the uncertainty accompanying the pandemic (Tanir et al, 2020). More specifically, Tanir et al. (2020) claimed cleanliness as well as handwashing obsessions and compulsions have increased during the viral outbreak. These symptoms are especially complicated to treat during normal times, but during the pandemic, these safety measures are highly encouraged which makes these behaviors even trickier intervention targets. Further, IU jeopardizes fear extinction (Pincotti et al., 2021). Therefore, skillful application of creative exposure-based techniques is essential. These procedures are ways children and adolescents can "show they can" tolerate uncertainty and approach heretofore dreaded experiences (Kendall et al., 2017). In the peri-pandemic era, there are abundant naturally occurring opportunities for exposure. In addition, clinicians may conduct many experiments in an imaginal manner. Of course, exposures require modifications during the pandemic and several recent articles delineate considerations for alterations (McKay et al., 2020; Sheu et al., 2020; Storch et al., 2020). Finally, multiple engaging, graduated, and creative exposures are available to help young patients tolerate uncertainty. Table 1 provides two suggestions for creative exposures with pediatric patients.

\section{Concluding Comments and Future Directions}

The world is struggling through a once-in-a-century public health crisis. The COVID-19 pandemic and its sequelae are contributing to multiple adverse circumstances, which in turn, leads to likely surges in pediatric health-related anxieties. Further, many individuals will experience "re-entry anxiety" when the pandemic officially ends (Sanderson et al., 2020). However, due to the unprecedented and sudden nature of the pandemic, the state of the science and clinical practice were somewhat caught unprepared. Nonetheless, understanding the pandemic's effects and developing clinical strategies to mitigate young patients' distress is imperative. Ideally, this article provides a clinical heuristic which facilitates conceptualization and targeted interventions.

IU likely represents a diathesis for anxiety-related symptoms and a logical transdiagnostic target for intervention. Identifying and treating IU potentially helps ameliorate young peoples' emotional and behavioral responses to the COVID-19 pandemic. Specifically, interventions targeting cognitive flexibility and increased exposure to uncertainty hold promise for building greater perceived control and tolerance for ambiguity. Therefore, application 
Table 1 CBT strategies and interventions

\begin{tabular}{ll}
\hline Strategy & Intervention \\
\hline Psychoeducation & Roller coaster metapho
\end{tabular}

Psychoeducation

Roller coaster metaphor

Brief description

Visual illusions (Ehrenreich-May \& Bilek, 2012)

Cognitive restructuring

Who's got the germ? (Friedberg et al., 2009)

Psychological immunity boosters (Friedberg et al., 2011)

Exposures/behavioral experiments Germ Scavenger Hunt (Friedberg et al., 2009)

Musical contaminants (Friedberg et al., 2009)
This metaphor communicates to young patients that they can cope with and approach uncertainty. Discussions of the fun parts of a rollercoaster ride might include some helpful questions such as: "What are the best/worst parts of riding roller coasters?", "What do you think the reasons are that people pay for riding a roller coaster?", and "What are the reasons you suppose cause people to ride a roller coaster again and again?

Illusions demonstrate that there can be multiple interpretations of a single circumstance. The takeaway from this exercise is that the way attention is directed shapes perception. Since these stimuli are ambiguous, they may also serve as a launching pad for graduated exposure to uncertainty

This game is a test of evidence procedure. Through the analysis of germ game cards, patients acquire a concrete database for evaluating their worries about contamination

This tool is based on a virus metaphor and is aimed at helping patients build skills to inoculate themselves against the perceived threat of uncertainty and anxiety. It relies on reattribution and problem-solving strategies (e.g., "What's another way to look at _.?" "What can you do to protect yourself from worries?" etc.)

Different "germs" are drawn on various small pieces of paper and scattered around various places in the clinic/office. The goal is to find and collect as many germs as possible. For the children to "win," they must touch various surfaces to get the germ and then properly wash hands. The experience is debriefed, a conclusion is crafted and then placed on a coping card

This procedure is based on the familiar musical chairs game. In this game, contaminated objects take the place of chairs. Players pass around the "contaminated" objects and the person who is holding the contaminant is the winner when the music stops. Thus, the child who holds onto the object longest is the champion of existing methods that mitigate IU in pediatric patients as well as the development of new ones that could help is recommended.

While CBT approaches to anxiety are empirically supported and widely applicable to diverse pediatric populations (Norris \& Kendall, 2020), traditionally marginalized populations are often disadvantaged by a lack of access to proper behavioral health care. The pandemic likely exacerbates this untoward circumstance. However, delivering these interventions in integrated pediatric health care settings offers potential in narrowing disparities. Stigma is reduced and access is increased with these services (Asarnow et al., 2017). Additionally, these settings typically emphasize prevention and early intervention.
The pandemic stimulated the growth of telehealth which can incorporate CBT interventions and be applied in integrated settings. Virtual service delivery facilitates convenience and ecological validity (Comer \& Timmons, 2019). Several regulatory barriers to telemedicine and telepsychiatry are removed due to the pandemic which somewhat minimizes access problems. However, the digital divide disproportionately negatively impacts marginalized populations (Fegert et al., 2020; Stancin, 2020). Therefore, creative solutions for attenuating the divide are needed during the pandemic and beyond (Kaslow et al., 2020).

Finally, improved and expanded psychological services will be needed to propel the recovery from the aftermath of the pandemic. The peri-pandemic period is a critical period 
for intervention planning and implementation. Equipped with the tools to address psychological sequelae, psychologists are tasked with building resilience in the face of uncertainty to increase self-efficacy and decrease worry. Increased behavioral health literacy for patients, caregivers, stakeholders, and policymakers will be crucial in raising awareness regarding psychiatric/psychological concerns. Better integration of accessible services into macro-systems such as schools, primary care settings, and community organizations, holds the potential to improve clinical and reduce behavioral health inequities in the peri- as well as post-pandemic periods.

Authors contributions All authors whose names appear on the submission made substantial contributions to the conceptualization, literature search, and/or critically revised this work.

Funding This work is not funded.

\section{Declarations}

Conflict of interest Robert D. Friedberg receives book royalties from Guilford, Springer. John Wiley, Routledge, and Professional Resource Press. He also serves on the training/speaking faculty of the Beck Institute for Cognitive Behavioral Therapy and Research. Jennifer K. Paternostro receives book royalties from Springer. All other authors declare no conflict of interest.

Ethical approval No human or animal data were collected as part of this manuscript.

Consent for publication All authors whose names appear on this submission approved the content.

Human and Animal Rights and Informed Consent This article does not contain any studies with human or animal subjects performed by any of the authors.

\section{References}

Abbott, A. (2021). COVID'S mental health toll: Scientists track surge in depression. Nature, 590, 194-195.

American Academy of Pediatrics \& Children's Hospital Association (2021). Children and COVID-19: State data report -8/12/21. https://www.aap.org/en/pages/2019-novel-coronavirus-covid19-infections/children-and-covid-19-state-level-data-report. Accessed 15 August 2021.

Alegria, M., Vallas, M., \& Pumariega, A. J. (2010). Racial and ethnic disparities in pediatric mental health. Child and Adolescent Psychiatric Clinics, 19, 759-774.

Asarnow, J. R., Kolko, D. J., Miranda, J., \& Kazak, A. E. (2017). The pediatric patient-centered medical home: Innovative models for improving behavioral health. American Psychologist, 72, 13-27.

Asmundson, G. J. G., Abramowitz, J. S., Richter, A. A., \& Whedon, M. (2010). Health anxiety: Current perspectives and future directions. Current Psychiatry Reports, 12, 306-312.

Asmundson, G. J. G., \& Taylor, S. (2020). How health anxiety influences responses to viral outbreaks like COVID-19: What all decision-makers, health authorities, and health care professionals need to know. Journal of Anxiety Disorders, 71, 102211.

Beesdo-Baum, K., Jenjahn, E., Höfler, M., Lueken, U., Becker, E. S., \& Hoyer, J. (2012). Avoidance, safety behavior, and reassurance seeking in generalized anxiety disorder. Depression and Anxiety, 29, 948-957.

Bryant, D. J., Oo, M., \& Damian, A. J. (2020). The rise of adverse childhood experiences during the COVID-19 pandemic. Psychological Trauma: Theory, Research, Practice, and Policy, 12, S193-S194.

Carleton, R. N. (2016). Into the unknown: A review and synthesis of contemporary models involving uncertainty. Journal of Anxiety Disorders, 39, 30-43.

Cervin, M., Perrin, S., Olsson, E., Aspvall, K., Geller, D. A., Wilhelm, S., McGuire, J., Lázaro, L., Martínez-González, A. E., Barcaccia, B., Pozza, A., Goodman, W. K., Murphy, T. K., Seçer, İ, Piqueras, J. A., Rodríguez-Jiménez, T., Godoy, A., Rosa-Alcázar, A. I., Ruiz-Garcia, I., ... Mataix-Cols, D. (2020). The centrality of doubting and checking in the network structure of obsessive-compulsive symptom dimensions in youth. Journal of the American Academy of Child \& Adolescent Psychiatry, $59,880-889$.

Chorpita, B. F., \& Barlow, D. A. (1998). The development of anxiety: The role of control in the early environment. Psychological Bulletin, 124, 3-21.

Comer, J. S., Roy, A. K., Furr, J. M., Gotimer, K., Beidas, R. S., Dugas, M. J., \& Kendall, P. C. (2009). The Intolerance of Uncertainty Scale for Children: A psychometric evaluation. Psychological Assessment, 21, 402-411.

Comer, J.S., \& Timmons, A. (2019). The other side of the coin: Computer-meditated interactions may afford opportunities for enhanced empathy in clinical practice. Clinical Psychology: Science \& Practice, 26, e/2308.

Cronbach, L. J., \& Meehl, P. E. (1955). Construct validity in psychological tests. Psychological Bulletin, 52, 281-302.

Czeisler, M. É., Lane, R. I., Petrosky, E., Wiley, J. F., Christensen, A., Njai, R., Weaver, M. D., Robbins, R., Facer-Childs, E. R., Barger, L. K., Czeisler, C. A., Howard, M. E., \& Rajaratnam, S. M. W. (2020). Mental health, substance use, and suicidal ideation during the COVID-19 pandemic-United States, June 24-30, 2020. MMWR. Morbidity and Mortality Weekly Report, 69, 1049-1057.

Ducat, L., Philipson, L. H., \& Anderson, B. J. (2014). The mental health comorbidities of diabetes. Journal of the American Medical Association, 312, 691.

Dugas, M. J., Gagnon, F., Ladouceur, R., \& Freeston, M. H. (1998). Generalized anxiety disorder: A preliminary test of a conceptual model. Behaviour Research and Therapy, 36, 215-226.

Dugas, M. J., Laugesen, N., \& Bukowski, W. M. (2012). Intolerance of uncertainty, fear of anxiety, and adolescent worry. Journal of Abnormal Child Psychology, 40, 863-870.

Ehrenreich-May, J., \& Bilek, E. L. (2012). The development of a transdiagnostic, cognitive behavioral group intervention for childhood anxiety disorders and co-occurring depression symptoms. Cognitive and Behavioral Practice, 19, 41-55.

Evans, S. C., Blossom, J. B., \& Fite, P. J. (2020). Exploring longitudinal mechanisms of irritability in children: Implications for cognitive-behavioral intervention. Behavior Therapy, 51, 238-252.

Fegert, J. M., Vitiello, B., Plener, P. L., \& Clemens, V. (2020). Challenges and burden of the Coronavirus 2019 (COVID-19) pandemic for child and adolescent mental health: A narrative review to highlight clinical and research needs in the acute phase and the long return to normality. Child and Adolescent Psychiatry and Mental Health, 14, 1-11.

Friedberg, R. D., Gorman, A. A., Hollar-Wilt, L., Biuckians, A., \& Murray, M. (2011). Cognitive behavioral therapy with youth for 
busy child psychiatrists and other mental health professionals. Routledge.

Friedberg, R. D., \& McClure, J. M. (2015). Clinical practice of cognitive therapy with children and adolescents: The nuts and bolts ( $2^{\text {nd }}$ Ed.). Guilford.

Friedberg, R. D., McClure, J. M., \& Garcia, J. H. (2009). Cognitive therapy techniques for children and adolescents. Guilford.

Gillett, C. B., Bilek, E. L., Hanna, G. L., \& Fitzgerald, K. D. (2018). Intolerance of uncertainty in youth with obsessive-compulsive disorder and generalized anxiety disorder: A transdiagnostic construct with implications for phenomenology and treatment. Clinical Psychology Review, 60, 100-108.

Golberstein, E., Wen, H., \& Miller, B. F. (2020). Coronavirus disease 2019 (COVID-19) and mental health for children and adolescents. JAMA Pediatrics, 174, 819.

Haig-Ferguson, A., Cooper, K., Cartwright, E., Loades, M. E., \& Daniels, J. (2020). Practitioner review: Health anxiety in children and young people in the context of the COVID-19 pandemic. Behavioural and Cognitive Psychotherapy, 49, 1-15.

Hearn, C. S., Donovan, C. L., Spence, S. H., \& March, S. (2017a). A worrying trend in social anxiety: To what degree are worry and its cognitive factors associated with youth social anxiety disorder? Journal of Affective Disorders, 208, 33-40.

Hearn, C. S., Donovan, C. L., Spence, S. H., March, S., \& Holmes, M. C. (2017b). What's the worry with social anxiety? Comparing cognitive processes in children with generalized anxiety disorder and social anxiety disorder. Child Psychiatry \& Human Development, 48, 786-795.

Hebert, E. A., \& Dugas, M. J. (2019). Behavioral experiments for intolerance of uncertainty: Challenging the unknown in the treatment of generalized anxiety disorder. Cognitive and Behavioral Practice, 26, 421-436.

Higa-McMillan, C. K., Francis, S. E., Rith-Najarian, L., \& Chorpita, B. F. (2016). Evidence base update: 50 years of research on treatment for child and adolescent anxiety. Journal of Clinical Child \& Adolescent Psychology, 45, 91-113.

Imran, N., Zeshan, M., \& Pervaiz, Z. (2020). Mental health considerations for children and adolescents in COVID-19 pandemic. Pakistan Journal of Medical Sciences, 36, S67-S72.

Inchausti, F., MacBeth, A., Hasson-Ohayon, I., \& Dimaggio, G. (2020). Psychological intervention and COVID-19: What we know so far and what we can do. Journal of Contemporary Psychotherapy, 50, 243-250.

Jiao, W. Y., Wang, L. N., Liu, J., Fang, S. F., Jiao, F. Y., PettoelloMantovani, M., \& Somekh, E. (2020). Behavioral and emotional disorders in children during the COVID-19 epidemic. The Journal of Pediatrics, 221, 264-266.e1.

Kaslow, N. J., Friis-Healy, E. A., Cattie, J. E., Cook, S. C., Cromwell, A. L., Cullum, K. A., Del Rio, C., Marshall-Lee, E. D., LoPilato, A. M., Vanderbroek-Stice, L., Ward, M. C., White, D. T., \& Farber, E. W. (2020). Flattening the emotional distress curve: A behavioral health response strategy for COVID-19. American Psychologist, 75, 875-886.

Kendall, P.C., Crawford, E.A., Kagan, E.R., Furr, J.M., \& Podell, J.L. (2017) Child-focused treatment for anxiety. In J.R Weisz \& A.E.Kazdin (Eds.), Evidence-based psychotherapies for children and adolescents ( $3^{\text {rd }}$ Ed., pp. 17-34). Guilford

Kertz, S., \& Woodruff-Borden, J. (2013). The role of metacognition, intolerance of uncertainty, and negative problem orientation in children's worry. Behavioural and Cognitive Psychotherapy, 41, 243-248.

Lieberman, L., Gorka, S. M., Sarapas, C., \& Shankman, S. A. (2016). Cognitive flexibility mediates the relation between intolerance of uncertainty and safety signal responding in those with panic disorder. Cognition and Emotion, 30, 1495-1503.
Liu, J. J., Bao, Y., Huang, X., Shi, J., \& Lu, L. (2020). Mental health considerations for children quarantined because of COVID-19. The Lancet Child \& Adolescent Health, 4, 347-349.

Loades, M. E., Chatburn, E., Higson-Sweeney, N., Reynolds, S., Shafran, R., Brigden, A., Linney, C., McManus, M. N., Borwick, C., \& Crawley, E. (2020). Rapid systematic review: The impact of social isolation and loneliness on the mental health of children and adolescents in the context of COVID-19. Journal of the American Academy of Child \& Adolescent Psychiatry, 59, 1218-1239.e3.

Mamelund, S.-E. (2018). 1918 pandemic morbidity: The first wave hits the poor, the second wave hits the rich. Influenza and Other Respiratory Viruses, 12, 307-313.

Marques de Miranda, D., da Silva Athanasio, B., Sena Oliveira, A. C., \& Simoes-e-Silva, A. C. (2020). How is COVID-19 pandemic impacting mental health of children and adolescents? International Journal of Disaster Risk Reduction, 51, 101845.

McKay, D., Minaya, C., \& Storch, E. A. (2020). Conducting exposure and response prevention treatment for contamination fears during COVID-19: The behavioral immune system impact on clinician approaches to treatment. Journal of Anxiety Disorders, 74, 102270.

Mertens, G., Gerritsen, L., Duijndam, S., Salemink, E., \& Engelhard, I. M. (2020). Fear of the coronavirus (COVID-19): Predictors in an online study conducted in March 2020. Journal of Anxiety Disorders, 74, 102258.

Moore, J. T., Ricaldi, J. N., Rose, C. E., Fuld, J., Parise, M., Kang, G. J., Driscoll, A. K., Norris, T., Wilson, N., Rainisch, G., Valverde, E., Beresovsky, V., Agnew Brune, C., Oussayef, N. L., Rose, D. A., Adams, L. E., Awel, S., Villanueva, J., Meaney-Delman, D., ... COVID-19 State, Tribal, Local, and Territorial Response Team. (2020). Disparities in incidence of COVID-19 among underrepresented racial/ethnic groups in counties identified as hotspots during June 5-18, 2020-22 States, February-June 2020. MMWR. Morbidity and Mortality Weekly Report, 69, 1122-1126.

Nelson, B. D., Liu, H., Sarapas, C., \& Shankman, S. A. (2016). Intolerance of uncertainty mediates the relationship between panic and the startle reflex in anticipation of unpredictable threat. Journal of Experimental Psychopathology, 7, 172-189.

Norris, L. A., \& Kendall, P. C. (2020). Moderators of outcome for youth anxiety treatment: Current findings and future directions. Journal of Clinical Child and Adolescent Psychology. https://doi. org/10.1080/15374416.2020.1833337

Oliver, A. M., Wright, K. D., Kakadekar, A., Pharis, S., Pockett, C., Bradley, T. J., Tomczak, C. R., \& Erlandson, M. C. (2020). Health anxiety and associated constructs in children and adolescents with congenital heart disease: A CHAMPS cohort study. Journal of Health Psychology, 25, 1355-1365.

Osmanağaoğlu, N., Creswell, C., \& Dodd, H. F. (2018). Intolerance of uncertainty, anxiety, and worry in children and adolescents: A meta-analysis. Journal of Affective Disorders, 225, 80-90.

O’Sullivan, T. L., \& Phillips, K. P. (2019). From SARS to pandemic influenza: The framing of high-risk populations. Natural Hazards, 98, 103-117.

Palitz, S. A., Davis, J. P., \& Kendall, P. C. (2019a). Anxiety disorders. In M. J. Prinstein, E. A. Youngstrom, E. J. Mash, \& R. A. Barkley (Eds.), Treatment of disorders in childhood and adolescence (Fourth edition, pp. 281-310). Guilford.

Palitz, S. A., Rifkin, L. S., Norris, L. A., Knepley, M., Fleischer, N. J., Steinberg, L., \& Kendall, P. C. (2019). But what will the results be?: Learning to tolerate uncertainty is associated with treatmentproduced gains. Journal of Anxiety Disorders, 68, 102146.

Pateraki, E., Vance, Y., \& Morris, P. G. (2018). The interaction between asthma and anxiety: An interpretative phenomenological analysis of young people's experiences. Journal of Clinical Psychology in Medical Settings, 25, 20-31. 
Phillips, N., Park, I.-W., Robinson, J. R., \& Jones, H. P. (2020). The perfect storm: COVID-19 health disparities in US Blacks. Journal of Racial and Ethnic Health Disparities. Advance online publication. https://doi.org/10.1007/s40615-020-00871-y.

Pincotti, C. Reimann, B., \& Abramowitz J. S. (2021). Intolerance of uncertainty and obsessive-compulsive symptoms. Journal of Anxiety Disorders, 351334588.

Rachman, S. (1977). The conditioning theory of fear acquisition: A critical examination. Behavior Research and Therapy, 15, 375-387.

Radanovic, A., Micic, I., Pavolovic, S., \& Krstic, K. (2021). Don't think that kids aren't noticing: Indirect pathways to children's fear of COVID-19. Frontiers in Psychology, 635952.

Rask, C. U., Gehrt, T. B., Rimvall, M. K., \& Frostholm, L. (2020). Health anxiety: Conceptualization and future directions. Zeitschrift Für Psychologie, 228, 141-144.

Read, K. L., Comer, J. S., \& Kendall, P. C. (2013). The Intolerance of Uncertainty Scale for Children (IUSC): Discriminating principal anxiety diagnoses and severity. Psychological Assessment, 25, 722-729.

Rifkin, L. S., \& Kendall, P. C. (2020). Intolerance of uncertainty in youth: Psychometrics of the intolerance of uncertainty index-A for children. Journal of Anxiety Disorders, 71, 102197.

Rifkin, L. S., \& Kendall, P.C. (2020b). The role of intolerance of uncertainty in anxiety disorders. Unpublished manuscript, Department of Psychology, Temple University.

Rodriquez, E. M., Gulbas, L. E., Horner, S., Alba-Suarez, J., GeorgeJones, J., Davidson, S., Lehning, E., Esperanza, C., \& Alvarado, C. (2020). Stress and coping in pediatric asthma: The experiences of low-SES Latinx families. Clinical Practice in Pediatric Psychology, 8, 126-138.

Sanderson, W. C., Arunagiri, V., Funk, A. P., Ginsburg, K. L., Krychiw, J. K., Limowski, A. R., Olesnycky, O. S., \& Stout, Z. (2020). The nature and treatment of pandemic-related psychological distress. Journal of Contemporary Psychotherapy, 50, 251-263.

Satici, B., Saricali, M., Satici, S. A., \& Griffiths, M. D. (2020). Intolerance of uncertainty and mental wellbeing: Serial mediation by rumination and fear of COVID-19. International Journal of Mental Health and Addiction, Advance online publication, https://doi. org/10.1007/s11469-020-00305-0.

Shahrbabaki, P. M., Dehghan, M., Maazallahi, M., \& Asadi, N. (2021). Fear and anxiety in girls aged 7 to 11 years old and related factors during the coronavirus pandemic. Clinical Child Psychology and Psychiatry. Advance online publication, https://doi.org/10.1177/ 13591045211013873.
Shelby, G. D., Shirkey, K. C., Sherman, A. L., Beck, J. E., Haman, K., Shears, A. R., Horst, S. N., Smith, C. A., Garber, J., \& Walker, L. S. (2013). Functional abdominal pain in childhood and longterm vulnerability to anxiety disorders. Pediatrics, 132, 475-482.

Sheu, J. C., McKay, D., \& Storch, E. A. (2020). COVID-19 and OCD: Potential impact of exposure and response prevention therapy. Journal of Anxiety Disorders, 76, 102314.

Simon, N. M., Saxe, G. N., \& Marmar, C. R. (2020). Mental health disorders related to COVID-19-related deaths. Journal of the American Medical Association, 324, 1493-1494.

Stancin, T. (2020). Reflections on changing times for pediatric integrated primary care during COVID-19 pandemic. Clinical Practice in Pediatric Psychology, 8, 217-219.

Storch, E. A., McGuire, J. F., \& McKay, D. (Eds.). (2018). The clinician's guide to cognitive-behavioral therapy for childhood obsessive-compulsive disorder. Academic Press.

Storch, E. A., Schneider, S. C., Guzick, A., McKay, D., \& Goodman, W. K. (2020). Impact of COVID-19 on exposure and response prevention for obsessive-compulsive disorder: Present and postpandemic considerations. Psychiatry Research, 292, 113310.

Tanir, Y., Karayagmurlu, A., Kaya, I., Kaynar, T. B., Turkmen, G., Pambasan, B. N., Meral, Y., \& Coskun, M. (2020). Exacerbation of obsessive-compulsive disorder symptoms in children and adolescents during the COVID-19 pandemic. Psychiatry Research, $293,113363$.

Taylor, S. (2019). The psychology of pandemics: Preparing for the next global outbreak of infectious disease. Cambridge Scholars Publishing.

Taylor, S., \& Asmundson, G. J. G. (2004). Treating health anxiety: A cognitive-behavioral approach. Guilford.

Valenzuela, J., Crosby, L. E., \& Harrison, R. R. (2020). Commentary: Reflections on the COVID-19 pandemic and health disparities in pediatric psychology. Journal of Pediatric Psychology, 45, 839-841.

Villadsen, A., Thorgaard, M. V., Hybel, K. A., Sondergaard Jensen, J., Thomsen, P. H., \& Rask, C. U. (2017). Health anxiety symptoms in children and adolescents diagnosed with OCD. European Child and Adolescent Psychiatry, 26, 241-251.

Publisher's Note Springer Nature remains neutral with regard to jurisdictional claims in published maps and institutional affiliations. 